\title{
Developing [60]Fullerene Nanomaterials for Better Photodynamic Treatment of Non-Melanoma Skin Cancers
}

\author{
Maciej Serda,* Grzegorz Szewczyk, Olga Krzysztyńska-Kuleta, Julia Korzuch, Mateusz Dulski, \\ Robert Musiol, and Tadeusz Sarna
}

Cite This: ACS Biomater. Sci. Eng. 2020, 6, 5930-5940

Read Online

\section{ACCESS | \\ 山ll Metrics \& More \\ Article Recommendations \\ Supporting Information}

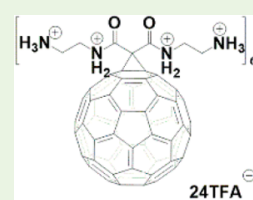

HEXAKISAMINO-C 60
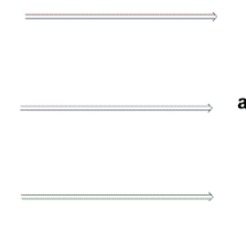

withoxicity, negligible e without LED irradiation

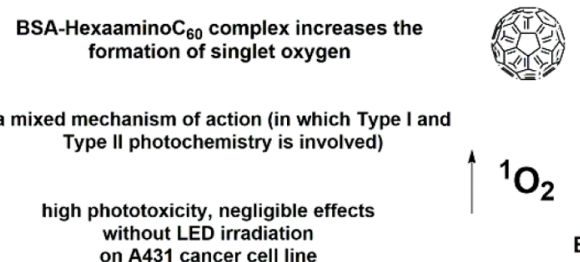

BOVINE SERUM ALBUMIN

ABSTRACT: Skin cancer is the most common cancer in the U.S.A. and Europe. Its subtype, squamous skin carcinoma (SCC), if allowed to grow, has the potential to metastasize and can become deadly. Currently, carbon nanomaterials are being developed to treat cancer due to their attractive physicochemical and biological properties such as an enhanced permeability effect and their ability to produce reactive oxygen species. Here, we describe the synthesis of two water-soluble aminofullerenes $\left(\mathrm{MonoaminoC}_{60}\right.$ and Hexakisamino $\mathrm{C}_{60}$ ), which were evaluated as novel [60]fullerene based photosentizers exhibiting anticancer properties. Moreover, the previously described neutral glycofullerene GF1 and its peracetylated lipophilic precursor MMS48 were compared with the aminofullerenes for their ability to generate reactive oxygen species and oxidize lipids. Remarkably, the generation of singlet oxygen and a superoxide radical by Hexakisamino $\mathrm{C}_{60}$ was found to be markedly elevated in the presence of bovine serum albumin and $\mathrm{NADH}$, respectively. Mechanistic studies of lipid peroxidation using cholesterol as a unique reporter molecule revealed that although all four fullerene nanomaterials primarily generated singlet oxygen, superoxide anion was also formed, which suggest a mixed mechanism of action (in which Type I and Type II photochemistry is involved). The [60]fullerene derivative $\mathrm{HexakisaminoC}_{60}$ was also studied for its phototoxicity in squamous skin cancer cell line (A431) using the MTT test and propidium iodide staining. KEYWORDS: [60]fullerene, non-melanoma skin cancer, photodynamic therapy, singlet oxygen, EPR spin trapping, lipid peroxidation

\section{INTRODUCTION}

Non-melanoma skin cancer (NMSC) is a serious malignant disease, which frequently occurs in older Caucasian patients and is categorized into two subgroups: basal cell carcinoma (BCC) and squamous cell carcinoma (SCC). ${ }^{1,2}$ While metastatic BCC is rarely diagnosed, ${ }^{3,4}$ metastatic SCC is characterized by a specific proliferation of invasive squamous cells and has an annual incidence of approximately $4 \%$. Despite its statistically low mortality, this malignancy causes considerable problems in the healthcare systems in Europe, the U.S.A., and Australia. A plethora of risk factors are involved in melanoma and NMSC pathogenesis including UV and ionizing radiation, and the occurrence of alterations in the oncogenes/ tumor suppressor genes such as BRAF, PTEN, and TP53. ${ }^{5}$ The metastatic potential, mortality rates, and reoccurrence are higher for SCC than for BSC, and the current clinical treatment options include surgical excision, radiation therapy, chemotherapy, and any combination of the above. ${ }^{6}$ Photodynamic therapy has been used as a successful treatment method in clinical practice with the topical use of 5aminolevulinic acid methyl ester (MAL-PDT) in patients suffering from basal cell carcinoma. ${ }^{7}$ Some novel chemotherapeutic strategies are also under development for the treatment of skin cancer including the use of the inhibitors of the protein tyrosine kinases such as EGFR and non-receptor Src kinases. ${ }^{8,9}$

The use of nanomedical approaches has been extensively explored for both diagnosing and treating skin cancers, including EGFR-targeted immunoliposomes, 5-ALA nanoconjugates with polylactic acid and engineered gold nanoparticles. ${ }^{10-12}$ Engineered carbon nanomaterials are promising new approaches, mainly for their cancer photodynamic therapy (PDT) and antimicrobial photodynamic inactivation (PDI) applications. ${ }^{13,14}$ The water-soluble fullerene derivatives tend

Received: June 23, 2020

Accepted: September 3, 2020

Published: September 3, 2020 
to be great candidates for photosensitizers because of the high triplet yields and the long triplet lifetime of the $\mathrm{C}_{60}$ cage, which facilitate their interaction with molecular oxygen. ${ }^{15}$ The pioneering studies performed by the Hamblin and Wilson groups, which were mainly focused on the Bingel-Hirsch monoadducts and functionalized pyrrolidinofullerenes, demonstrated the utility of water-soluble aminofullerenes in PDT. ${ }^{16-19}$ An interesting addition to the traditional $\mathrm{C}_{60^{-}}$ based photosensitizers are the Gadolinium-containing endohedral fullerenes and the derivatives of $\mathrm{Gd} @ \mathrm{C}_{82}$, which are also used as MRI-contrast agents and to stimulate immunological responses followed by modulating the tumor microenvironment. $^{20,21}$ Despite weak absorption of [60]fullerenes in the deep-penetrating NIR region of the spectrum (above $700 \mathrm{~nm}$ ), they are able to perform the Type 1 and Type 2 photochemical reactions and are highly resistant to photobleaching, which make them an attractive option as photosensitizers for most PDT applications. ${ }^{17}$ Application of low-penetrating blue light illuminations can be overcome by using femtosecond lasers in two-photon excitation experiments or upconverting nanoparticles such as $\mathrm{NaYF}_{4}$ with $\mathrm{Yb}^{3+} / \mathrm{Er}^{3+}$ dopants via covalent conjugation/coating absorption to the photosensitizer scaffold. $^{22}$

Previous studies, performed by our group, demonstrated that the water-soluble glycofullerenes were photoactive and they localized inside the nuclear envelope of the pancreatic stellate cells (PSCs). ${ }^{23}$ Moreover, the results that were obtained from the cited studies revealed that glycofullerenes could effectively inhibit the nonreceptor tyrosine kinases, with a selectivity toward the FYN A protein, which is an important potential target for skin cancers, even in the presence of the FBS proteins. $^{24}$ This observation could be of use in combinational therapies because tyrosine kinase inhibitors are also being investigated in the treatment of skin cancers. ${ }^{25}$ At the same time, several reports have demonstrated interactions between the albumin proteins and the photosensitizers, which played an important role in their biodistribution within the tumor tissues. ${ }^{26}$ The water-soluble fullerenes are well-known for their interactions with human serum albumin, which forms a stable complex with the [60]fullerene tris-malonic acid $\left(C_{3} \text { isomer called } \mathrm{CF}\right)^{27}$ or PCBM fullerene. ${ }^{28}$ Interestingly, although no effects on the quantum yield of ${ }^{1} \mathrm{O}_{2}$ production was observed for a bovine serum albumin (BSA) complex with [60]fullerene tris-malonic acid, the triplet lifetime of HSA-CF was significantly shortened, compared to the noncomplexed fullerene. ${ }^{29}$

On the basis of our previous studies, we wanted to evaluate the possibility of treating non-melanoma skin cancers using the [60] fullerene derivatives. Although our previous studies on pancreatic stellate cells using a water-soluble glycofullerene (Sweet- $C_{60}$ ) demonstrated that it was photoactive, no biophysical studies were performed and therefore its photochemistry remains unknown. ${ }^{23}$ Here, the physicochemical properties of the neutral glycofullerene GF1 (a water-soluble analog of Sweet- $C_{60}$ ) and its peracetylated lipophilic analog MMS48 were compared with those of two cationic aminofullerenes- Momoamino $\mathrm{C}_{60}$ and HexakisaminoC $_{60}$ (Figure 1 ). The formation of singlet oxygen was confirmed by measuring its phosphorescence at $1270 \mathrm{~nm}$ in the presence and absence of albumin (BSA). Using EPR spin trapping and HPLC with electrochemical detection, we monitored cholesterol peroxidation and protein oxidation, which revealed that the synthesized fullerene nanomaterials were promising

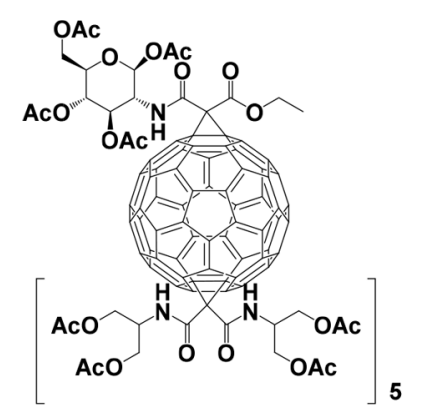

MMS48

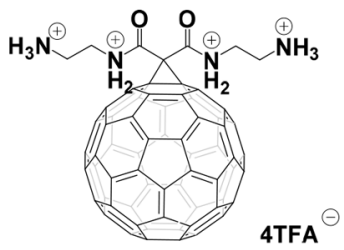

MONOAMINO- $\mathrm{C}_{60}$

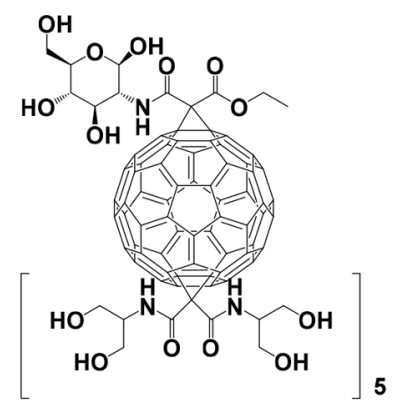

GF1

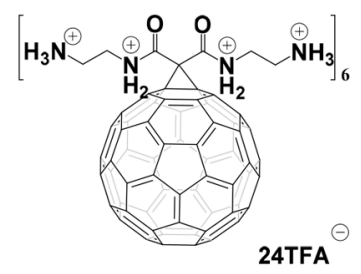

HEXAKISAMINO-C 60
Ac=acyl

TFA= trifluoroacetic acid
Figure 1. Chemical structures of the fullerenes GF1, MMS48, MONOAMINOC $_{60}$, and HEXAKISAMINOC 60 .

photosensitizers that could be used in anticancer photodynamic therapy. Both singlet oxygen and oxygen radicals can cause oxidative damage to vital targets in cells by starting chain reactions of peroxidation in the cell membranes and disrupting the enzymatic or structural functions of proteins. Lipid and protein peroxides can also damage other important targets in cells. ${ }^{30,31}$ The ability to cause photooxidized damage to cellular targets was confirmed using phototoxicity assays in a cellular model of squamous skin cancer.

\section{EXPERIMENTAL SECTION}

Materials. All of the compounds that were used were reagent grade or better and the solvents were used as-received, unless otherwise specified. The following reagents were used as-received: $\mathrm{C}_{60}$ (99.5\%, SES RESEARCH, U.S.A.), 2-amino-1,3-propanediol (AK Scientific), DBU (1,8-diaza-bicyclo [5.4.0]undec-7-ene, Sigma-Aldrich), acetic anhydride (Acros Organics), malonic acid methyl ester (Acros Organics), $\mathrm{CBr}_{4}$ (Sigma-Aldrich), EDCI hydrochloride $[\mathrm{N}$ ethyl- $N^{\prime}$-(3-(dimethylamino)propyl)carbodiimide hydrochloride, Acros Organics], $N$-hydroxysuccinimide (Sigma-Aldrich), potassium carbonate (Sigma-Aldrich), trifluoroacetic acid (Acros Organics), and trityl chloride (Acros Organics). All of the solvents that were used to prepare the fullerene nanomaterials were prepared according to the procedures in the literature by distilling them with calcium hydride and were used immediately. The nuclear magnetic resonance spectra were measured on a Bruker Avance III $500 \mathrm{MHz}$ NMR Spectrometer with TMS as the internal standard. The MS spectra for the waterinsoluble fullerenes were collected using an Autoflex II MALDI-TOF 
mass spectrometer, and for the water-soluble [60]fullerene derivatives, an MS electrospray ionization time-of-flight (ESI-microTOF) mass spectrometer was used; both instruments were from Bruker Daltonics Inc. (Fremont, CA, U.S.A.). The final dialysis purification of the water-soluble fullerene nanomaterials was performed on Pall Microsep centrifugal membranes with the molecular cutoffs at 1 and 3 $\mathrm{kDa}$. The purity of all of the compounds was assessed using an Agilent1260, which was equipped with a DAAD detector at $260 \mathrm{~nm}$ and an RP-column: Eclipse plus C18 $(3.5 \mu \mathrm{m})$; flow $0.5 \mathrm{~mL} / \mathrm{min}$. The Fourier transform infrared (FTIR) measurements were carried out using an Agilent Cary 640 FTIR spectrometer, which was equipped with a standard source and a DTGS Peltier-cooled detector. The aminofullerene powders were mixed with $\mathrm{KBr}$ and measured in the transmittance mode in the $400-4000 \mathrm{~cm}^{-1}$ range. The spectrum was recorded at 32 accumulations and a spectral resolution of $4 \mathrm{~cm}^{-1}$. The obtained data were analyzed using the baseline, water and carbon dioxide corrections.

Synthesis of the [60]Fullerene Derivatives. The glycofullerenes MMS48 and GF1 were synthesized according to a previously described methodology. ${ }^{24}$ The synthetic protocol for preparing the aminofullerenes (Monoamino- $\mathrm{C}_{60}$ and Hexakisamino- $\mathrm{C}_{60}$ ) is depicted in Scheme S1 of the Supporting Information (SI), which presents the detailed NMR and mass spectrometry analyses, DLS, and zeta potential measurements (see SI).

$N^{1}$-Tritylethane-1,2-Diamine (1). Ethylenediamine (24.96 mmol; $1.5 \mathrm{~g}$ ) was dissolved in $40 \mathrm{~mL}$ of dichloromethane, and then anhydrous potassium carbonate $(24.96 \mathrm{mmol} ; 3.45 \mathrm{~g}$ ) was added to the solution. Next, a trityl chloride solution $(12.48 \mathrm{mmol} 3.48 \mathrm{~g})$ in DCM was added to the reaction mixture over $40 \mathrm{~min}$ and was stirred at room temperature for 3 days. After this time, the white solid was filtered off, and the obtained filtrate was extracted three times by adding $3 \times 50 \mathrm{~mL}$ of deionized water. The organic phase was dried over magnesium sulfate and purified using column chromatography (DCM: $\mathrm{MeOH}, 10 / 1, v / v ; R_{\mathrm{f}}=0.16$ ). The final product was obtained as a white solid with a yield of $82 \%$ and $\mathrm{mp}$ as $93{ }^{\circ} \mathrm{C} .{ }^{32}$

$N^{1}, N^{3}$-Bis(2-(tritylamino)ethyl)malonamide (2). Tritylethane-1,2diamine $(3.08 \mathrm{mmol} ; 0.93 \mathrm{~g}$ ) was dissolved in $100 \mathrm{~mL}$ of methanol and then dimethyl malonate $(1.5 \mathrm{mmol} ; 0.2 \mathrm{~g})$ was added dropwise for $10 \mathrm{~min}$. The obtained reaction mixture was refluxed for $3 \mathrm{~h}$ and then stirred at room temperature for 2 days to obtain a reddish solution of the desired malonate. After that time, the reaction mixture was evaporated, and the obtained brownish oil was dissolved in $50 \mathrm{~mL}$ methylene chloride and extracted three times with $50 \mathrm{~mL}$ of deionized water. The organic phase was evaporated, which produced the desired bismalonamide as a brown, oily product with a final yield of $69 \%$, which was used for the further Bingel-Hirsch cyclopropanation reactions with no additional purifications (the high resolution mass spectrometry of malonate 2 is depicted in Figure S2 of the SI).

Monoamino $C_{60}$. The fullerene $\mathrm{C}_{60}(0.5 \mathrm{mmol} ; 360 \mathrm{mg})$ was added to the freshly distilled toluene $(450 \mathrm{~mL})$, mixed for $5 \mathrm{~min}$ using a magnetic stirrer, which was followed by an additional suspension using an ultrasonic bath for $15 \mathrm{~min}$ (the temperature of the $\mathrm{C}_{60}$ solution did not exceed $\left.50{ }^{\circ} \mathrm{C}\right)$. Then, a dichloromethane solution $(10 \mathrm{~mL})$ of bismalonamide $2(0.5 \mathrm{mmol} ; 333.6 \mathrm{mg})$ and $\mathrm{CBr}_{4}(1$ mmol; $331.63 \mathrm{mg}$ ) was added to the solution of $\mathrm{C}_{60}$, which was followed by the dropwise addition of a solution of DBU $(0.625 \mathrm{mmol}$; $95.1 \mathrm{mg}$ ) in $5 \mathrm{~mL}$ of DCM; the reaction was allowed to stir for $2 \mathrm{~h}$ at room temperature. After that time, the fullerene monoadduct (3) was isolated using the two-step flash chromatography procedure. For this purpose, the reaction mixture was first purified on a precolumn using toluene as the mobile phase-the biggest fraction was from the unreacted fullerene. Then, the final product was eluted from the column using a mixture of $\mathrm{CH}_{2} \mathrm{Cl}_{2} / \mathrm{MeOH} 5: 1$ to 2:1. The brown filtrate was evaporated in vacuo to form a brown solid with a $28 \%$ yield and the structure of fullerene monoadduct (3), which was confirmed by NMR spectroscopy (see SI) as well as MALDI-TOF spectrometry (Figure S1). The final hydrolysis of trityl-protected fullerene monoadduct (3) was performed using a $20 \%$ dichloromethane solution of trifluoroacetic acid. Briefly, $200 \mathrm{mg}$ of the fullerene monoadduct (3) was dissolved in a $20 \mathrm{~mL}$ mixture of DCM and $20 \%$ trifluoroacetic acid $(1 / 1, v / v)$. The solution was stirred at room temperature for 7 days, during which the changes in the color of the aqueous layer from transparent to red-orange were observed. Next, $50 \mathrm{~mL}$ of water was added to the solution, and the phases were separated in a separatory funnel and the aqueous phase was collected and evaporated. The Monoamino $\mathrm{C}_{60}$ was purified on centrifugal membranes using a $1 \mathrm{kDa}$ filter membrane (Pall Corporation, U.S.A.), and the upper layer of the membrane was washed four times with 15 $\mathrm{mL}$ of distilled water. Then, the desired fullerene nanomaterial (4) was passed through syringe filters $(0.2 \mu \mathrm{m})$ to sterilize it and to remove any larger agglomerates. The sample was then freeze-dried in a lyophilizer, which resulted in a reddish mesh powder that was stored at $-20{ }^{\circ} \mathrm{C}$. The desired Monoamino $\mathrm{C}_{60}$ was characterized using NMR, infrared spectroscopy, and ESI-MS (see the SI).

Hexakisamino $_{60}$. A fullerene monoadduct (4) $(0.2 \mathrm{mmol} ; 278$ $\mathrm{mg}$ ) was dissolved in $10 \mathrm{~mL}$ of DCM and then $100 \mathrm{~mL}$ of toluene was added under intensive stirring at room temperature. In a separate 25 $\mathrm{mL}$ vial, $15 \mathrm{~mL}$ of a chloroform solution of malonate (2) $(2 \mathrm{mmol}$; $1350 \mathrm{mg}$ ) and carbon tetrabromide (4 mmol; $1324 \mathrm{mg}$ ) was prepared. The contents of the vial were added to the solution of Monoamino $_{60}$ for $5 \mathrm{~min}$, after which, a $3 \mathrm{~mL}$ chloroform solution of DBU was prepared (362 mg; $2.4 \mathrm{mmol}$ ) to which $0.5 \mathrm{~mL}$ DBU solution was added every $60 \mathrm{~min}$. Next, the reaction mixture was stirred at room temperature for $48 \mathrm{~h}$, during which the color of the solution changed to orange. A [60]fullerene Hexakis adduct (5) was purified from the organic impurities using a flash column, first using methylene chloride and then eluting the final [60] fullerene derivative with an eluent that consisted of a mixture of DCM: $\mathrm{MeOH}(9: 1, v / v)$ and then the final $\mathrm{T}_{h}$ symmetrical Hexakis adduct of [60]fullerene was concentrated on a rotary evaporator. The fullerene derivative (5) was characterized using NMR spectroscopy (See Supporting Information and Figure S1). In order to remove the trityl-protecting group from the fullerene nanomaterial (5), the compound was hydrolyzed using $20 \%$ trifluoroacetic acid. Briefly, a sample of the compound (5) was dissolved in a mixture of $10 \mathrm{~mL}$ DCM and $10 \mathrm{~mL} 20 \%$ TFA. The solution was stirred at room temperature for 7 days, during which the color of the aqueous layer changed from transparent to orange. Next, $25 \mathrm{~mL}$ of water was added to the fullerene solution, extracted and then the aqueous phase was collected and evaporated. The Hexakisamino $\mathrm{C}_{60}$ was purified on centrifugal membranes using a 1 $\mathrm{kDa}$ filter membrane (Pall Corporation, U.S.A.), the top layer of the membrane was washed four times with $15 \mathrm{~mL}$ of distilled water and passed through syringe filters $(0.2 \mu \mathrm{m})$ to sterilize it and to remove any larger agglomerates. The [60]fullerene nanomaterial was then frozen at $-20{ }^{\circ} \mathrm{C}$ and freeze-dried, which resulted in a red powder that was then stored in a laboratory freezer at $-20{ }^{\circ} \mathrm{C}$. The Hexakisamino $\mathrm{C}_{60}$ was characterized using NMR and infrared spectroscopy and was confirmed using ESI-MS.

Singlet Oxygen Phosphorescence and EPR Spin Trapping. The near-infrared luminescence $(1270 \mathrm{~nm})$ was measured perpendicular to the excitation beam in the photon-counting mode using a thermoelectric-cooled NIR PMT module (H10330-45; Hamamatsu, Japan), which was equipped with a $1100 \mathrm{~nm}$ cutoff filter and an additional dichroic narrow-band NBP filter, selectable from the spectral range of 1150-1355 nm (NDC Infrared Engineering Ltd., Essex, U.K.). The data were collected using a computer-mounted PCI-board multichannel scaler (NanoHarp 250; PicoQuant GmbH, Berlin, Germany). Data analysis, including the first-order luminescence decay, which was fitted using the Levenberg-Marquardt algorithm, was performed using custom-written software. The acquisition time for obtaining the singlet oxygen phosphorescence signals was $20 \mathrm{~s}$. The EPR measurements were performed using a Bruker EMX-AA EPR spectrometer (Bruker BioSpin, Rheinstetten, Germany). The EPR samples were run using a microwave power of $10.6 \mathrm{~mW}$, a modulation amplitude of $0.05 \mathrm{mT}$, center field $339.0 \mathrm{mT}$, scan width $8 \mathrm{mT}$, and scan time $21 \mathrm{~s}$.

The phosphate-buffered $(\mathrm{pD} 7.4,10 \mathrm{mmol}) \mathrm{D}_{2} \mathrm{O}$ solutions of the fullerene nanomaterials and TMPyP were excited in a $1 \mathrm{~cm}$-optical path quartz fluorescence cuvette (QA-1000; Hellma, Mullheim, Germany) using the monochromatic light pulses that were generated 


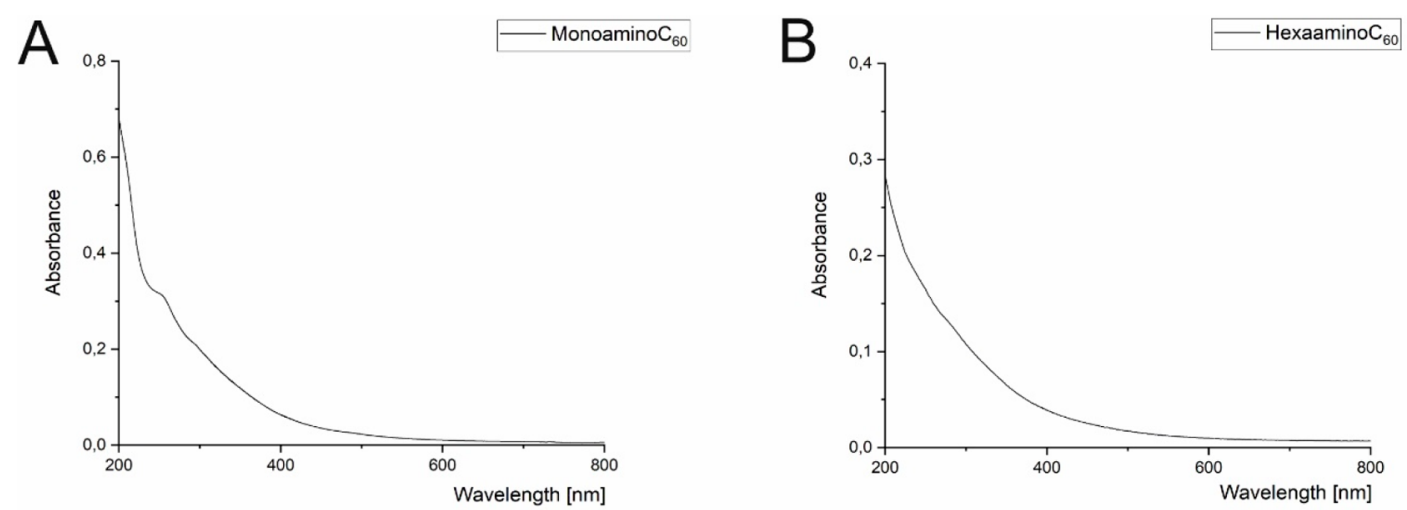

C

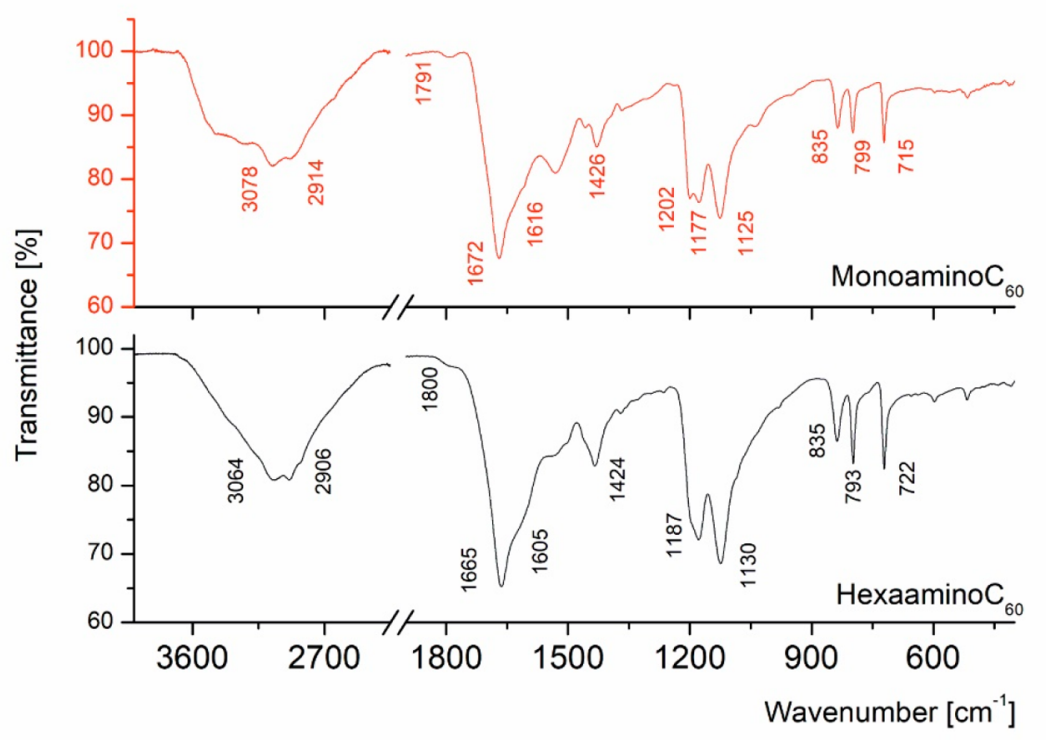

Figure 2. UV-vis and IR spectra of water-soluble [60]fullerenes Monoamino $\mathrm{C}_{60}$ and $\mathrm{Hexakisamino}_{60}$.

by an integrated nanosecond DSS Nd/YAG laser system, which was equipped with a narrow bandwidth optical parametric oscillator (NT242-1k-SH/SFG; Ekspla, Vilnius, Lithuania). The laser system delivered pulses at a $1-\mathrm{kHz}$ repetition rate and had a pulse energy up to several hundred microjoules in the visible region and up to several tens of microjoules in the UVA-UVB region. The [60]fullerene photosensitizers were photoexcited using a $429 \mathrm{~nm}$ wavelength. The absorbance of the samples was set to 0.27 in that wavelength. In order to adjust the photoexcitation energy in the experiments, a laser beam was attenuated with three pieces of wire mesh (light transmission $40 \%$ each). The quantum yield of singlet oxygen formation was obtained using 5,10,15,20-tetrakis(1-methyl-4-pyridinio) porphyrin) tetra( $p$ toluenesulfonate) (TMPyP) as the reference compound $(\varphi=0.75) .{ }^{33}$ For detection of radicals photogenerated by the studied [60]fullerens, EPR-spin trapping was employed, using DMPO as the spin trap at a concentration of $100 \mathrm{mM}$. Samples containing $0.1 \mathrm{mg} / \mathrm{mL}$ of appropriate fullerene nanomaterials in $80 \%$ DMSO were irradiated in EPR quartz flat cells in the resonant cavity with $402-508 \mathrm{~nm}(24$ $\mathrm{mW} / \mathrm{cm}^{2}$ ) light, which was derived from a $300 \mathrm{~W}$ high-pressure compact arc xenon lamp (Cermax, PE300CE13FM/Module300W; PerkinElmer Optoelectronics, GmbH, Wiesbaden, Germany). To control spectral irradiance, the system was equipped with a water filter, heat reflecting hot mirror, cutoff filter that blocked light below $390 \mathrm{~nm}$ and a blue additive dichroic filter 505FD64-25 (Andover Corporation, Salem, NH, U.S.A.).

Photobleaching of Hexakisamino $\mathrm{C}_{60}$. Stability of Hexakisami${ }^{n o C_{60}}$ was checked in PBS solution. Concentration was set to 0.05 $\mathrm{mg} / \mathrm{mL}$ and absorbance spectra was recorded. The sample was irradiated with blue light from the same source and the same power flux as used for cell phototoxicity $\left(445 \mathrm{~nm}, 20 \mathrm{~mW} / \mathrm{cm}^{2}\right)$. Absorbance was measured in 5 min intervals to check if any changes occurred.

HPLC Monitored Cholesterol and Liposomes Peroxidation. The HPLC analysis and electrochemical detection on a mercury drop was employed for cholesterol hydroperoxides detection. This method enables identification and quantification of cholesterol hydroperoxides of different origin, thus allowing us to determine the major mechanisms of lipids oxidation. ${ }^{34} 7 \alpha \beta-\mathrm{OOH}$ cholesterol hydroperoxides form as a result of cholesterol reaction with oxidizing radicals, while $5 \alpha-\mathrm{OOH}$ and $6 \alpha \beta-\mathrm{OOH}$ hydroperoxides are generated via the reaction with singlet oxygen. In brief, multilayered liposomes were prepared from a mixture of DMPC/cholesterol in 3:1 molar ratio. Liposomes were enriched with [60]fullerenes in PBS solution during the creation from dry lipid layers, with one exceptionfullerene nanomaterial MMS48 was added to chloroform solution of lipids, as it is totally water-insoluble, due to the presence of acetyl protecting groups. Liposomes were light-treated with $10 \mathrm{~mW} / \mathrm{cm}^{2}$ of blue light $(445 \mathrm{~nm})$, then lipids were extracted using modified Folch procedure, dried under nitrogen stream and frozen in $-20{ }^{\circ} \mathrm{C}$. For HPLC analysis the samples were dissolved in isopropanol and separated on $\mathrm{RP}-\mathrm{C}_{18}$ column. The mobile phase consisted of $72 \%$ methanol, $11 \%$ acetonitrile, $9 \%$ ultrapure $\mathrm{H}_{2} \mathrm{O}$ (containing $1 \mathrm{mM}$ of $\mathrm{NaClO}_{4}$ ), and $8 \%$ of isopropanol. To determine retention times for cholesterol hydroperoxides $(7 \alpha-\mathrm{OOH}$ and $5 \alpha-\mathrm{OOH})$ analytical standards were used. 
A

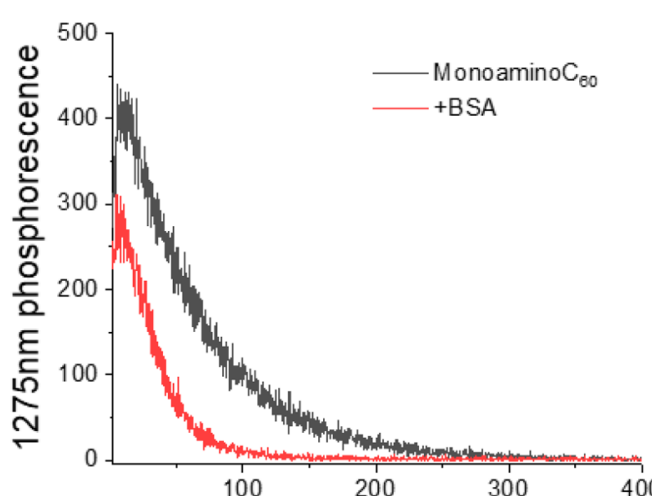

B

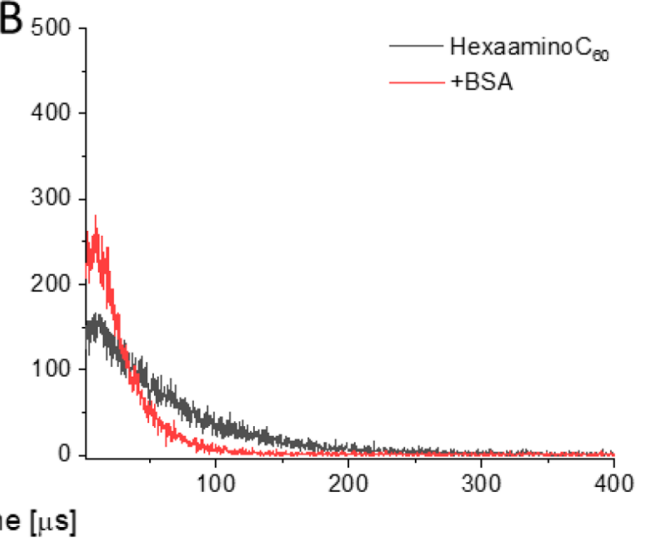

C

D

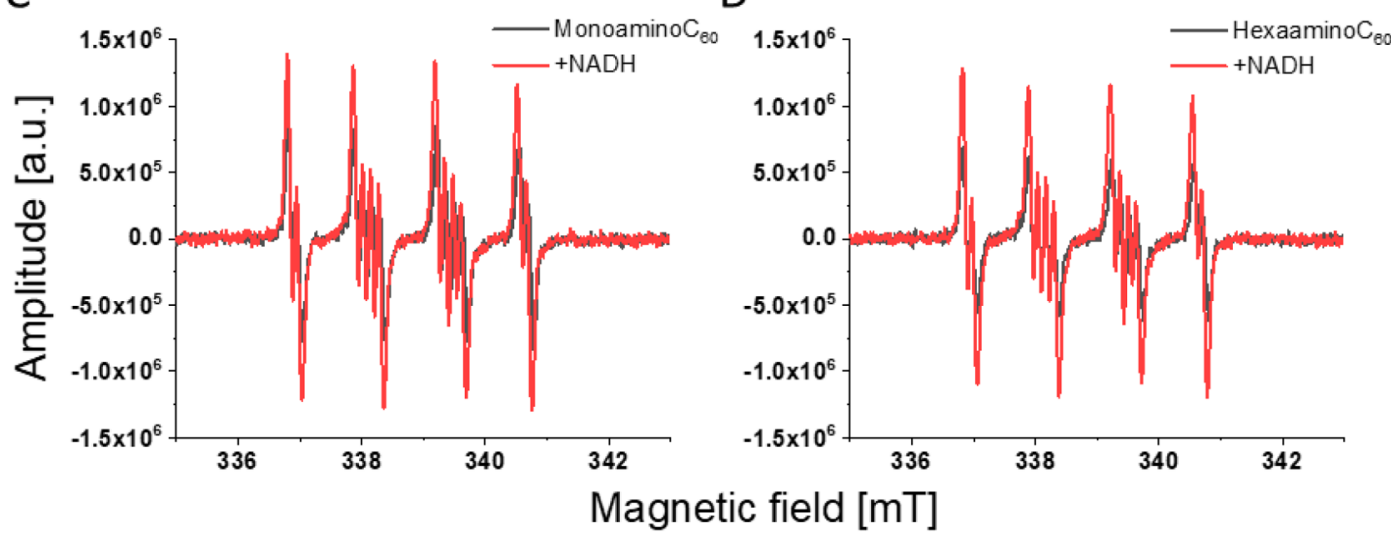

Figure 3. Singlet oxygen luminescence signals (A and B) after $429 \mathrm{~nm}$ laser pulse excitation observed in $\mathrm{D}_{2} \mathrm{O}$ solutions of $\mathrm{MonoaminoC}_{60}$ and Hexakisamino $_{60}$ in absence (black lines) or with an addition of $35 \mu \mathrm{M}$ of BSA (red line). DMPO spin trapping of respective $\mathrm{C}_{60}$ in $80 \%$ of DMSO (C and D) without (black trace) or with addition of $\mathrm{NADH}$ (red trace).

Bovine Serum Albumin Oxidation Using CBA Test. Coumarin boronic acid (CBA) reacts with protein hydroperoxides forming fluorescent product 7-hydroxycoumarin $(\mathrm{COH})$. This reaction can be used for quantification of protein oxidation. ${ }^{35}$ Stock solution $(2.5$ $\mathrm{mM}$ ) of bovine serum albumin (LabEmpire) was prepared in PBS directly before experiment and diluted to final concentration of 100 $\mu \mathrm{M}$. Hexakisamino $\mathrm{C}_{60}$ was added to samples to achieve desire concentrations of 50,10 , and $5 \mu \mathrm{g} / \mathrm{mL}$. Protein hydroperoxide scavenger ebselen in concentration of $100 \mu \mathrm{M}$ was added to one of the control samples. ${ }^{36}$ Samples were placed in a 96-well plate (black, with bottom transparent) and irradiated with $20 \mathrm{~mW} / \mathrm{cm}^{2}$ blue light (blue COB led light, $445 \mathrm{~nm}$ ) for $20 \mathrm{~min}$. Just after irradiation $200 \mathrm{U}$ of catalase was added for $5 \mathrm{~min}$ to all the samples to remove any hydrogen peroxide. CBA (final concentration $0.4 \mathrm{mM}$ ) in 10 times diluted PBS was added. Formation of fluorescent $\mathrm{COH}$ was monitored in $10 \mathrm{~min}$ intervals for $5 \mathrm{~h}$ using $360( \pm 15 \mathrm{~nm})$ as excitation and $465( \pm 20 \mathrm{~nm})$ as emission wavelength.

MTT Photocytotoxicity. Human squamous carcinoma A431 was obtained from the American Type Culture Collection (ATCC). The A431 cells were plated in 24-well plates at density of $35000 /$ well. Twenty-four hours after plating, the cells were incubated with highglucose DMEM that contained Hexakisamino $\mathrm{C}_{60}$ at different concentrations. Feeding was repeated two more times, at $24 \mathrm{~h}$ intervals. The day after the final feeding the cells were washed twice with PBS that contained calcium and magnesium ions, then irradiated for $15 \mathrm{~min}$ using a blue led light $(440 \mathrm{~nm})$ at a fluence rate of 20 $\mathrm{mW} / \mathrm{cm}^{2}$. Dark control cells were kept in the same conditions except for light exposure. After irradiation, the cells were provided by DMEM with $10 \%$ FBS. The cytotoxic effect of the photodynamic treatment was quantified $24 \mathrm{~h}$ after irradiation, using an MTT assay for the mitochondrial redox function. The MTT solution in DMEM with 10\% FBS was added to the treated and control culture wells (final concentration of $0.5 \mathrm{mg} / \mathrm{mL}$ ). After incubation for $30 \mathrm{~min}$ at 37 ${ }^{\circ} \mathrm{C}$, the culture medium was removed, and the remaining blue precipitate was solubilized in DMSO, followed by reading the absorbance at $560 \mathrm{~nm}$ in a plate reader (GENios Plus, Tecan Austria $\mathrm{GmbH}$ ). The results are reported as the percentage of the paired untreated controls. The experiments were repeated a minimum of three times.

Cellular PI Staining after PDT. To estimate the apoptotic effect of light induced Hexakisamino $\mathrm{C}_{60}, \mathrm{~A} 431$ cells were stained using fluorescent dye propidium iodide (PI) $24 \mathrm{~h}$ after irradiation, as described in a previously described protocol. ${ }^{37}$ In brief, propidium iodide (final concentration $100 \mu \mathrm{M}$ ) was added to the control and treated cells, and fluorescence images $(510-560 \mathrm{~nm}$ excitation/580 $\mathrm{nm}$ emission) were taken to detect PI-positive nuclei. Then, Triton X100 was added (final concentration $0.1 \%$ ), and fluorescence images were captured to quantify the total cell number in each field. The number of viable cells and the total number of cells per field were quantified using the ImageJ software with the Huang method ${ }^{38}$ for cell finding using a custom-written script by Dr. Łukasz Bujnowicz (Jagiellonian University, Poland).

\section{RESULTS AND DISCUSSION}

Chemistry. Synthesis and Physicochemical Properties of Aminofullerenes Monoamino $\mathrm{C}_{60}$ and Hexakisamino $\mathrm{C}_{60}$. On the basis of previously reported literature findings describing the use of fullerene nanomaterials in photodynamic therapy, we aimed to synthesize water-soluble [60]fullerene photosensitizers possessing multiamino groups, which are easily assessable utilizing a trityl function protection/deprotection approach. The fullerene scaffold has great potential to be chemically modified, enhancing its water-solubility, therefore 


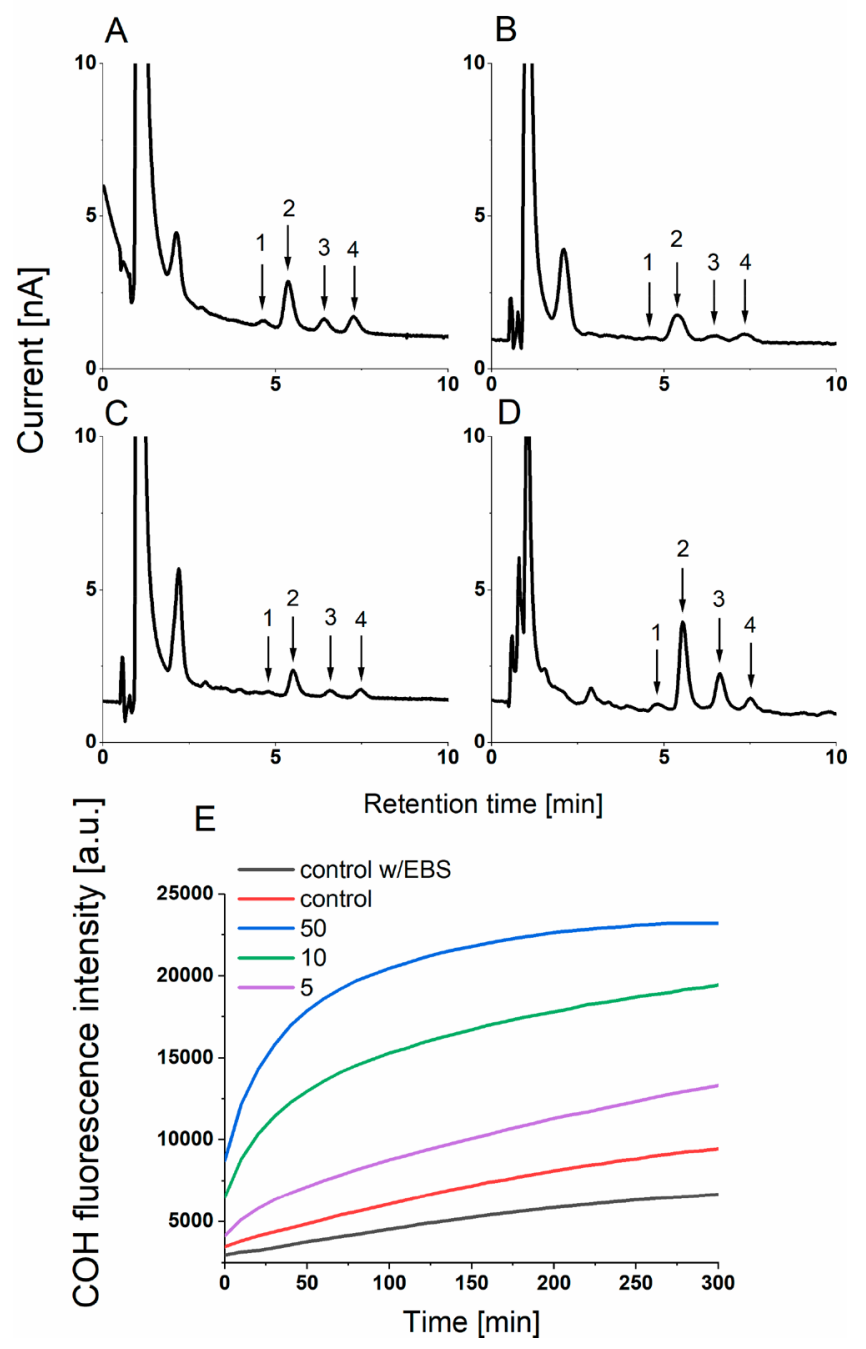

Figure 4. HPLC chromatograms of DMPC/cholesterol liposomes with four [60]fullerene derivatives (A, HexakisaminoC $\mathrm{C}_{60}$; $\mathrm{B}$, Monoamino $\left._{60} ; \mathrm{C}, \mathrm{GF} 1 ; \mathrm{D}, \mathrm{MMS} 48\right)$. The arrows indicate the cholesterol hydroperoxides with their characteristic retention times $(1,4.7 \mathrm{~min}-7 \alpha \beta-\mathrm{OOH} ; 2,5.5 \mathrm{~min}-5 \alpha-\mathrm{OOH}$; and 3 and $4,6.6$ and $7.5 \mathrm{~min}-6 \alpha \beta-\mathrm{OOH})$, respectively. Panel $\mathrm{E}$ shows the formation of the protein hydroperoxides that were determined using $\mathrm{COH}$.

the Bingel-Hirsh approach gives a possibility to modify its structure with specially designed malonates, thanks to the ability to control the cyclopropanation reaction and obtaining selected regioisomers, especially [60]fullerene monoadducts and Hexakisadducts with $T_{h}$ symmetry. This phenomenon was especially important for our biophysical comparative studies, because less substituted fullerenes seem to be more effective photosensitizers based on the studies performed by Hamblin et al. ${ }^{17,39}$ However, tailored designed [60]fullerene derivatives might be hard to accomplish, due to variations of the degree of malonate additions and complex addition patterns. To address these problems, we propose the use of malonamide (2) in the double Bingel-Hirsh protocol. ${ }^{23}$ The molecular ion peak of compound (2) was observed in the high resolution ESI mass spectrum at $673.3536 \mathrm{Da}$ (calculated for $\mathrm{C}_{45} \mathrm{H}_{45} \mathrm{~N}_{4} \mathrm{O}_{2}$, 673.35425 Da, Figure S3). The time-controlled reaction is stopped after $2 \mathrm{~h}$ to prevent formation on bisadduct regioisomers or used further for creation of highly symmetrical Hexakisadducts from more reactive monoadducts. An overview of whole synthetic strategy is depicted in Scheme S1 (see SI), starting with ethylenediamine core, we aimed to obtain trityl based symmetrical malonamide (2), but without using additional coupling agents, only by a gentle refluxing with dimethyl malonate. For all water-soluble fullerene nanomaterials ESI-spectrometry was used for detection of molecular peaks, but trityl-protected [60]fullerenes were measured by MALDI-TOF technique using DCTB matrix. The formation of [60]fullerene monoadduct (3) was confirmed by ${ }^{13} \mathrm{C}$ NMR spectroscopy based on its molecular symmetry (Figure S1, characteristic $\mathrm{C}_{60}$ signals from $2 \times 15 \mathrm{sp}^{2}$ carbon atoms between 145 and 139 ppm and one $\mathrm{sp}^{3}$ carbon at $70.4 \mathrm{ppm}$ ) and MALDI-TOF mass spectrometry with a molecular ion peak at $1436.309 \mathrm{Da}(\mathrm{M}-\mathrm{H}+2 \mathrm{Na}$, Figure $\mathrm{S} 4, \mathrm{M}-\mathrm{H}+2 \mathrm{Na})$. The desired MonoaminoC $\mathrm{C}_{60}$ was obtained by deprotection of trityl groups in $20 \%$ TFA, followed by membrane dialysis with $1 \mathrm{kDa}$ cutoff. It was further characterized by NMR spectroscopy and positively ionization ESI-MS with observed molecular ion peak $478.86 \mathrm{Da}[\mathrm{M}+\mathrm{H}]^{2+}$ (Figure S5). Next, a highly symmetrical [60]fullerene Hexakisadduct (5) was created using fullerene monoadduct (3) as a starting material, in a second Bingel-Hirsh reaction with an 10-fold excess of malonate (2) and $\mathrm{CBr}_{4}$ and controlled addition of DBU during 6 h. This double Bingel-Hirsh synthetic approach to [60]fullerene Hexakisadducts was described by our group earlier and generates increased yields of final products as well as reduced presence of different regioisomers in the reaction mixture (mainly tris- and tetrakisadducts as byproducts). The $T_{h}$ symmetry of [60]fullerene Hexakisadduct (5) was confirmed by ${ }^{13} \mathrm{C}$ NMR spectroscopy, which is expressed by a reduction of fullerene $\mathrm{sp}^{2}$ signals in the carbon spectrum. Only two signals ( 143.97 and $142.62 \mathrm{ppm}$ ) of fullerene $\mathrm{sp}^{2}$ carbons and one $\mathrm{sp}^{3}$ carbon of cyclopropane ring (70.4 ppm) could be observed in the carbon spectrum of Hexakisadduct (5) (Figure S2). The aforementioned hydrolysis protocol was carried out to obtain Hexakisamino $\mathrm{C}_{60}$ from a corresponding trityl protected fullerene derivative $(5)$ and the desired watersoluble [60]fullerene (6) was characterized by NMR spectroscopy and ESI mass spectrometry with detected molecular ion peak at $1839.3 \mathrm{Da}$ (positive mode, $50 \mathrm{mV},[\mathrm{M}+2 \mathrm{H}]^{+}$, Figure $\mathrm{S} 6 \mathrm{~A}$ ). The change of experimental setup during electrospray spectrometry measurements (to $300 \mathrm{mV}$ voltage), resulted in a rapid fragmentation of Hexakisamino $\mathrm{C}_{60}$, with observed molecular ion peak of a parent MonoaminoC $_{60}$ disodium fragment $\left[\mathrm{M}+2 \mathrm{Na}+\mathrm{H}_{2} \mathrm{O}\right]^{+}$.

The UV-vis spectra of two water-soluble aminofullerenes are presented in the Figure 2A,B. This experimental observation could be also partially explained by higher water solubility of HexakisaminoC ${ }_{60}$ (above $250 \mathrm{mg} / \mathrm{mL}$ ) in comparison to MonoaminoC ${ }_{60}$ (around $30 \mathrm{mg} / \mathrm{mL}$ ).

In the case of Monoamino $\mathrm{C}_{60}$, one characteristic absorption peak could be observed at $270 \mathrm{~nm}$. This local maximum is similar to the UV absorption spectra of pristine $\mathrm{C}_{60}$ fullerene in a toluene solution (maxima observed at $269 \mathrm{~nm}$ ), with only minimal absorption below $550 \mathrm{~nm}$ and negligible fluorescence. In electron spectrum of Hexakisadduct (6) no clear maxima was observed, which was also described for water-soluble glycofullerenes and other aminofullerenes. ${ }^{23,40}$ Additionally, for the same concentrations of aminofullerenes, the HexakisaminoC $_{60}$ spectrum was hypochromized for a given absorbance on the order of $45 \%$, which may be explained by formation of [60]fullerene aggregates. The DLS measurements performed on a Malvern Zetasizer illustrate that both aminofullerenes 


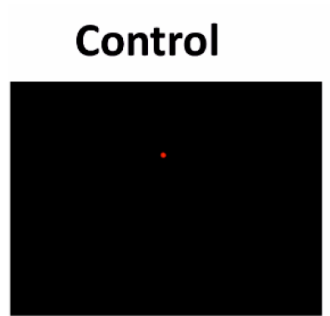

\section{$0.005 \mathrm{mg} / \mathrm{ml}$}
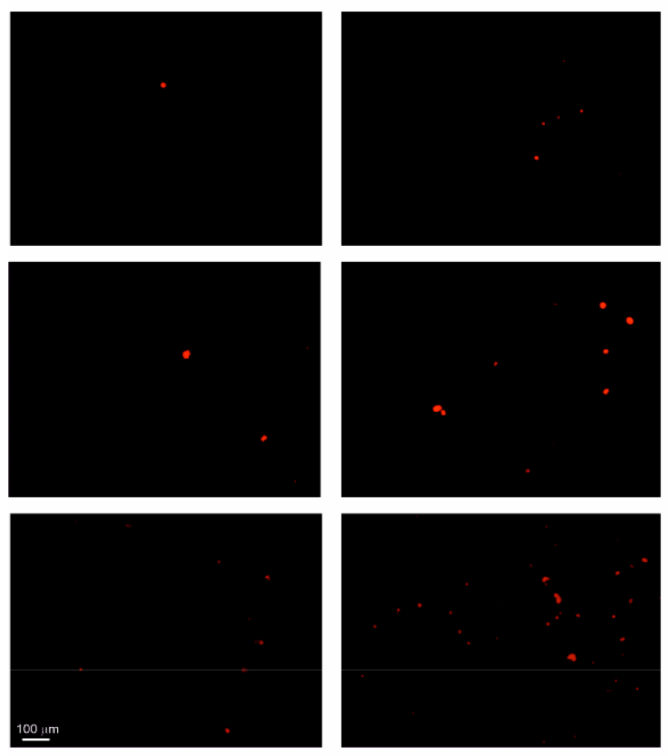
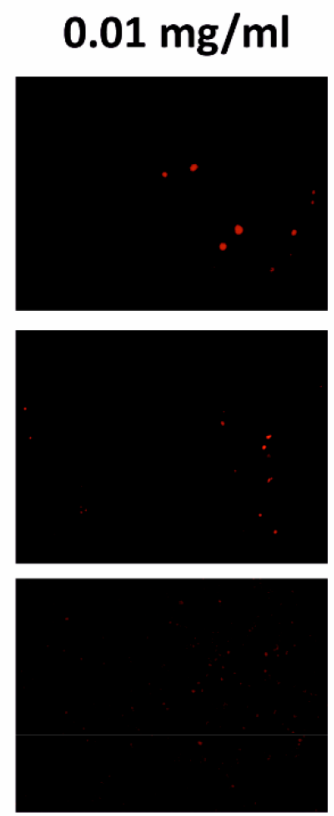

$0.05 \mathrm{mg} / \mathrm{ml}$
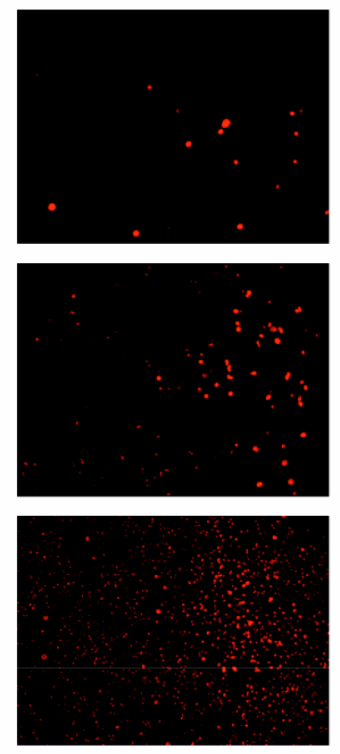

A

Dark

Green light

Blue light
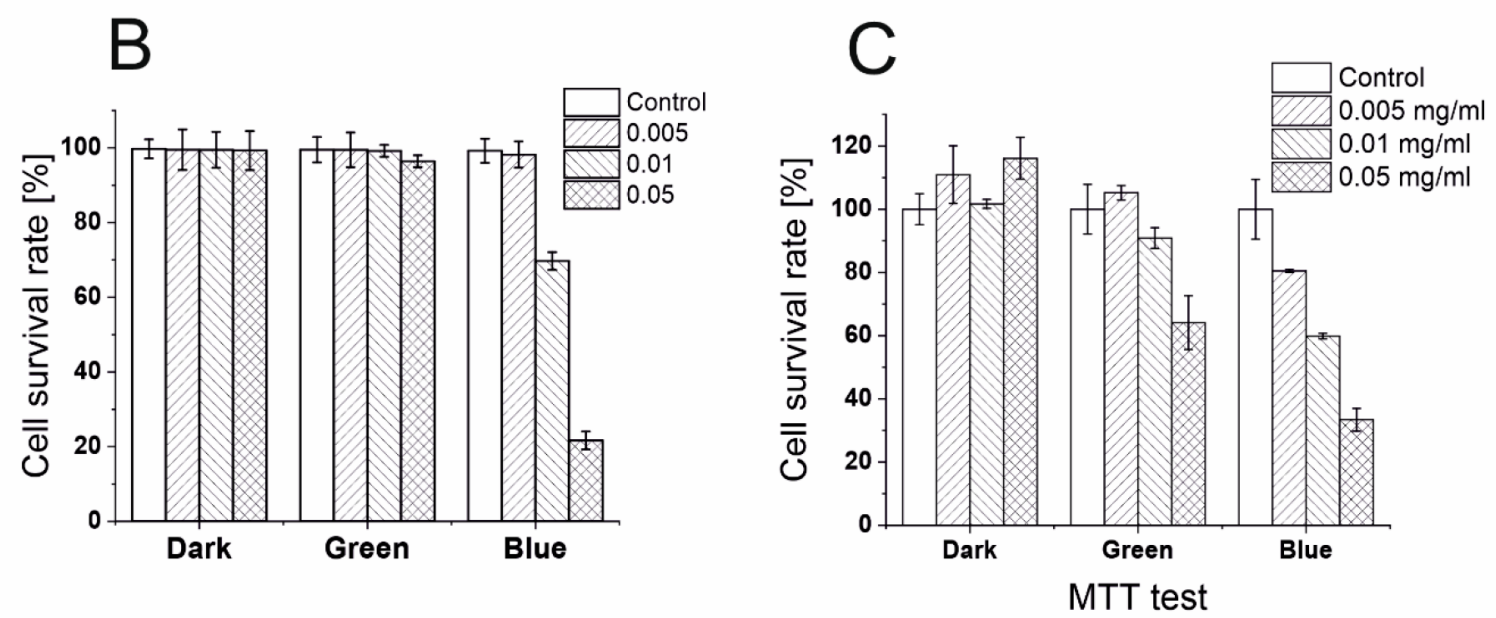

Figure 5. Microscopic images of the phototreated A431 cells that had been stained with propidium iodide (A); the results that were obtained after a mathematic picture analysis (B) of the same experiment, which was recalculated for cell survivability. The result of the MTT assay of the A431 cells after irradiation $(\mathrm{C})$; and different bars show the different Hexakisamino $\mathrm{C}_{60}$ concentrations.

form aggregates, which are in a dynamic equilibrium as described previously for fullerene Hexakisadduct $\mathrm{C}_{60}$ ser. $^{41}$ The Monoamino $_{60}$ forms larger aggregates around $354 \mathrm{~nm}$ with observed zeta potential at $+31 \mathrm{mV}$; in contrast Hexakisami$\mathrm{noC}_{60}$ seems to predominantly aggregate around $99 \mathrm{~nm}$, indicating a surface of charge of $+29 \mathrm{mV}$. Both aminofullerenes present a relatively good degree of stability, and the smaller aggregates and possibly a different morphology of Hexakisadduct aggregates may be partially explained by a different critical packing parameter $p$. $^{42}$

The infrared spectra of engineered water-soluble fullerenes (Monoamino $\mathrm{C}_{60}$ and Hexakisamino $\mathrm{C}_{60}$ ) have been analyzed considering two spectral regions: (1) $2250-3800 \mathrm{~cm}^{-1}$ and (2) $400-1900 \mathrm{~cm}^{-1}$ (Figure 2C). The bands arrangement found in relation to the Hexakisamino $\mathrm{C}_{60}$ and Monoamino $_{60}$ are quite similar, wherein small differences as for the number of bands, their intensity, or positions result from the number of functional groups anchored to the fullerene scaffold. Looking more precisely on the spectrum of Hexakisamino derivative of $\mathrm{C}_{60}$, region 1 is linked mainly to the overlapping signals originating from the symmetric and asymmetric stretching modes of $\nu\left(\mathrm{CH}_{2}\right)$ and $\nu\left(\mathrm{NH}_{x}\right)(\mathrm{x}=2,3)$. The band positions of amine groups (3064 and $2906 \mathrm{~cm}^{-1}$ ) relating to the band position of the typical amine result probably from the presence of inter- or intramolecular interactions. ${ }^{43}$ Similarly affected seems to be the position of the methylene bands which may be shifted toward higher wavenumbers due to the presence of positive charge located on the amine groups, in relation to a typical position of the methylene group within the alkene chain. ${ }^{44,45}$

An interesting phenomenon is also observed for the whole band arrangement of region 1, where bands are characterized by the high full width at half-maximum and high intensity, indicating a huge distribution and high number of $\mathrm{H}$-bonds with different donor-acceptor bonds lengths. According to this assumption, weak, medium, and strong hydrogen bonds are present, probably due to the high dynamicity of the system as well as the presence of TFA counterion, enforcing formation of the highly dynamic systems maintained by the $\mathrm{H}$-bonding system. A slightly different situation appeared in the case of 
aminofullerene monoadduct. Here, the position of two additional bands found at higher wavenumbers is closely related to the symmetric and asymmetric stretching modes of amine groups, typically reported in the literature for free or weakly involved in the hydrogen bonding scheme, $\mathrm{NH}_{2}$ groups. The other two bands observed in this region are slightly shifted toward higher wavenumbers in relation to the Hexakis aminofullerene, wherein its interpretation is similar like previously. As a result of such observations, the band arrangement of monoamino $\mathrm{C}_{60}$ may result from a much smaller number of functional units anchored to the fullerene core and their weaker influence in formation of the H-bonding.

The fingerprint (1) region of Hexakisamino $\mathrm{C}_{60}$ fullerene, especially at high wavenumbers is characterized by one maximum, strong in the intensity centered at $1665 \mathrm{~cm}^{-1}$, as well as a shoulder at $1605 \mathrm{~cm}^{-1}$ and one band low in the intensity located at $1800 \mathrm{~cm}^{-1}$. All of those bands are linked to the stretching vibration of carbonyl moieties, whereby their positions are indicated on the primary amides located within the organic chain (Figure 2). ${ }^{46}$ The position of low lying carbonyl bands may be explained two ways, as a result of the presence of hydrogen bonds or due to the occurrence of the $\beta$ diketone structure. $^{47,48}$

In turn, the low intensity band centered at $1800 \mathrm{~cm}^{-1}$ might explain taking into account counterion in which the halogen atoms are directly bonded to a carbonyl group that according to the theory absorb strongly at the presence of fluorine. Other bands with the maxima at 1424,1187 , and $1130 \mathrm{~cm}^{-1}$ may respectively be linked to the symmetric deformational modes of ethylenediamine groups, as well as skeletal vibration of alkane chain and deformational modes of methylene groups. In turn, the group of bands centered at $835,793,722 \mathrm{~cm}^{-1}$ are difficult in the interpretation, because of the overlapping character of various modes which may be activated at those wavenumbers. However, those bands may try to interpret as the asymmetric deformation modes of tertiary amides at 835 $\mathrm{cm}^{-1}$, the deformational mode within straight-chain alkanes at $793 \mathrm{~cm}^{-1}$ and CF at $726 \mathrm{~cm}^{-1}$. A lower number of functional units anchored to the fullerene core, resulted in some shift of bands toward lower or higher wavenumbers, i.e., a shift of carbonyl moieties, strongly involved in the formation of the $\mathrm{H}$ bonding scheme is correlated with the weakening of mutual interaction between donor-acceptor units. One can conclude that the smaller number of functional units anchored to the fullerene core, the weaker interaction between them could be observed. In addition, the position of bands linked to the modes corresponding to the ethylenediamine or the alkane chain is only slightly changed relating to the Hexakisamino $C_{60}$ but reveal the spatial rearrangement of this kind of functional groups.

Biophysics. The ability to cause photoinduced damage is a primary function of traditional as well as nanomaterial-based photosensitizers. In this study, we have shown that all four [60]fullerenes are able to produce reactive oxygen species (ROS). As depicted in Figure 3CD, the EPR spectra of spin adducts characteristic to spin trapping of superoxide anion by $\mathrm{DMPO}$ are being presented ${ }^{49}$ (for a simulated spectrum of DMPO-OOH adduct see SI Figure S21). Efficiency of that process was markedly increased by the presence of an external electron donor like $\mathrm{NADH}$ (Figures $3 \mathrm{CD}$, red traces). Although superoxide anion is not a very reactive compound, it can travel long distances inside cells and secondary reactions may oxidize targets far from its generation site. Singlet oxygen
$\mathrm{O}_{2}\left({ }^{1} \Delta_{\mathrm{g}}\right)$, however, is much more reactive and in cellular environment could react in close vicinity to its point of formation. Singlet oxygen formation was detected by a direct observation of a characteristic phosphorescence of $\mathrm{O}_{2}\left({ }^{1} \Delta_{\mathrm{g}}\right)$ at $1275 \mathrm{~nm}$ in photon-counting mode (Figure $3 \mathrm{AB}$ ). Experiments were conducted in phosphate $\mathrm{D}_{2} \mathrm{O}$ buffer to increase the lifetime of the generated singlet oxygen and to enhance the detection sensitivity. ${ }^{50}$ The quantum yield of singlet oxygen photogeneration for both aminofullerenes was obtained using TMAP as a standard and it was determined to be around 0.1 and 0.062 (HexakisaminoC $_{60}$ vs MonoaminoC $_{60}$, Figures S12 and S18); in the case of MMS48, the tetraphenylporphirine (TPP) was used as a standard, in a chloroform solution (Figure $\mathrm{S} 20$ ). Although it is not a high yield for Hexakisamino $\mathrm{C}_{60}$, in the presence of serum albumin the formation of singlet oxygen was markedly increased (Figure 3B), what was also measured quantitively (Figure S22). As expected, lifetime of singlet oxygen decreased in the presence of albumin, due to reaction with the protein (the corresponding rate constant being around $\left.7 \times 10^{8}\right){ }^{51}$ The elevated efficiency of singlet oxygen photogeneration observed for Hexakisamino $\mathrm{C}_{60}-\mathrm{BSA}$ complex, compared to Hexakisamino $C_{60}$ alone is noteworthy. Typically, complexation of a photosensitizer molecule by albumin is accompanied by substantial reduction in the photosensitizer efficiency to photogenerate singlet oxygen. Such a phenomenon has been observed for WST-11 and WST19 photosensitizers. ${ }^{52,53}$ The increased efficiency of photogeneration of singlet oxygen by Hexakiskisamino $\mathrm{C}_{60}-\mathrm{BSA}$, compared to Monamino $\mathrm{C}_{60}-\mathrm{BSA}$ remains rather puzzling, suggesting different mechanism of BSA binding. This may be caused by a different mode of binding affinities of synthesized aminofullerenes to IIA and IIIA subdomains of BSA. The larger and more substituted and $T_{h}$ symmetrical Hexakisami${ }_{\text {noC }}{ }_{60}$ could be easier to bind to hydrophobic pockets of BSA. Moreover, the computational studies performed by the group of Papadopoulos indicated that positively charged aminofullerens and fullerene carboxylic acids that negatively charged groups attached to the fullerene core may be necessary to enhance ligand-HAS interactions. ${ }^{54}$ Only a limited number of cationic compounds have been reported to exempt this rulethis observation may be true for fullerene nanomaterial Hexakisamino $\mathrm{C}_{60}$, but further computational studies should be performed. Moreover, a recent studies by Di Giosia et al. have also reported the shielding effects of proteins in the case of $\mathrm{C}_{60} @$ lysozyme hybrid, which was visualized by the increase in singlet oxygen generation and reduction of quenching by water molecules. ${ }^{55,56}$ In our case, HexakisaminoC ${ }_{60}$ is forming smaller aggregates than MonoaminoC ${ }_{60}(99 \mathrm{~nm} v s 354 \mathrm{~nm}$ ), which may also favor its better ability to produce ${ }^{1} \mathrm{O}_{2}$ after binding with BSA.

The analysis of cholesterol peroxidation products induced by the studied [60]fullerenes reveal that at least in liposomes, the main oxidizing species is singlet oxygen (Figure 4ABCD). The peak from $7 \mathrm{ab}-\mathrm{OOH}$ (depicted in Figure 4 as 1 , with a retention time of $4.7 \mathrm{~min}$ ) is barely visible and could come from internal rearrangements of singlet oxygen-related hydroperoxides. ${ }^{34}$ It would suggest that in a lipid microenvironment, the excited triplet states of fullerene nanomaterials are much more prone to energy transfer, resulting in singlet oxygen production. This effect is especially pronounced for the water insoluble form-MMS48 (Figure 4D). From three tested water-soluble fullerene derivatives, Hexakisamino $\mathrm{C}_{60}$ was found to be most effective in the photooxidation of cholesterol 
(Figure 4A). Additionally, Hexakisamino $\mathrm{C}_{60}$ nanomaterial, as well as other tested fullerene nanomaterials were found to be quite resistant to photobleaching in conditions used for photodynamic treatment (Figures S14-S17). As for cellular and tissue applications, the presence of serum albumin is inevitable, we have chosen HexakisaminoC $_{60}$ derivative for further studies in cell phototoxicity experiments using squamous skin carcinoma model. The ability to photooxidize proteins by Hexakis derivative of $\mathrm{C}_{60}$ was further investigated using coumarin boronic acid assay (Figure 4E). The obtained results clearly show a dose-dependent increase in the amount of fluorescent $\mathrm{COH}$, which is a product of reaction of nonfluorescent CBA and bovine serum albumin hydroperoxides. This observation confirms that during blue LED light irradiation, Hexakisamino $\mathrm{C}_{60}$ is able to also oxidize proteins.

Photodynamic Therapy. To determine cell phototoxicity, the A431 cell line of a non-melanoma skin cancer was used. The cells were fed with Hexakisamino $C_{60}$ fullerene for three consecutive days. During that time, no dark toxicity in the range of the concentrations that were used in the experiment was observed (Figure 5). Phototoxicity was pronounced for the cells that were irradiated with blue light $(445 \mathrm{~nm})$, while a significantly weaker effect was observed when the cells were irradiated with green light $(500-580 \mathrm{~nm})$. This observation is consistent with the relative absorbance of the $\mathrm{C}_{60}$ derivatives. Two methods were used to detect phototoxicity-determining the mitochondrial activity (MTT assay, Figure 5C) and cell membrane permeability (propidium iodide test, Figure $5 \mathrm{AB}$ ). Although the observed effects for both tests were photosensitizer-dose dependent, the MTT test produced more pronounced results that showed photodynamic damage, which may suggest that the photoinduced damage primarily occurs in the cell mitochondria and cytosol. This observation is in agreement with previous studies on glycofullerenes as well as with the fluorescently labeled fullerene derivative $\mathrm{C}_{60}$ serPF, which have demonstrated that water-soluble [60]fullerene derivatives tend to accumulate mainly in the nuclear envelope and cytosol of cancer cells. ${ }^{23,57}$ The green light exposure caused negligible effects in the membrane permeability assay even at the highest concentration of the nanophotosensitizer that was used, while for the same conditions, the cell viability that was measured by the MTT test was reduced to $60 \%$ (Figure 5). In both of those experiments, the blue LED light irradiation resulted in a substantial increase in cell death with a $0.05 \mathrm{mg} / \mathrm{mL}$ concentration of HexakisaminoC ${ }_{60}$ reducing the cell survival rate to around $20 \%$. It was expected that there would be a lower efficiency under green light irradiation compared to the effective absorbance of Hexakisamino $\mathrm{C}_{60}$ in the corresponding regions of the absorbance spectrum. Although blue light has a low tissue penetration, in potential in vivo application, it can enable very precise targeting, which would reduce the damage to non-malignant tissues. ${ }^{58}$ The results that were obtained using blue light irradiation clearly showed that this compound has the properties of a promising photosensitizer that could be used in topical applications.

\section{CONCLUSIONS}

We synthesized two novel aminofullerenes-Monoamino $\mathrm{C}_{60}$ and Hexakisamino $\mathrm{C}_{60}$ and compared their biophysical properties based on studies of ROS formation, and lipid and protein peroxidation. On the basis of the observation that BSAHexakisamino $\mathrm{C}_{60}$ complex increased the formation of singlet oxygen, we selected Hexakisamino $\mathrm{C}_{60}$ for further cellular studies, which confirmed its high phototoxicity, which had negligible effects without LED irradiation. Additionally, we do believe that further molecular docking studies should also be performed to visualize differences of BSA binding to a different $[60]$ fullerene derivatives. The future $3 \mathrm{D}$-spheroid or in ovo experiments should be performed to evaluate it as a photosensitizer in the photodynamic therapy of skin cancer, especially using a higher concentration of the [60]fullerene derivative and green LED irradiation due to its higher tissue penetration properties.

\section{ASSOCIATED CONTENT}

\section{sI Supporting Information}

The Supporting Information is available free of charge at https://pubs.acs.org/doi/10.1021/acsbiomaterials.0c00932.

Chemistry: Synthetic protocol for obtaining monoaminoC $_{60}$ and hexakisamino $C_{60} ; \mathrm{NMR}$ of substrates and fullerene derivatives; high resolution ESI mass spectrometry of malonate (2); MALDI-TOF mass spectrometry of water insoluble fullerene (3); ESI mass spectrometry of water-soluble aminofullerenes (4) and (6); DLS studies of water-soluble aminofullerenes (4) and (6); Zeta potential measurements of water-soluble aminofullerenes (4) and (6); HPLC chromatogram of peroxides standards used for lipid peroxidation studies; Biophysics: quantum yield of singlet oxygen formation of hexakisamino $\mathrm{C}_{60}(6)$; EPR spin trapping and singlet oxygen phosphorescence measurements for GF1; and photobleaching of Hexakisamino $\mathrm{C}_{60}$ (PDF)

\section{AUTHOR INFORMATION}

\section{Corresponding Author}

Maciej Serda - Institute of Chemistry, University of Silesia in Katowice, Katowice 40-007, Poland; 이이.org/0000-00034926-5782; Email: maciej.serda@us.edu.pl

\section{Authors}

Grzegorz Szewczyk - Faculty of Biochemistry, Biophysics, and Biotechnology, Jagiellonian University, Krakow 30-387, Poland

Olga Krzysztyńska-Kuleta - Faculty of Biochemistry, Biophysics, and Biotechnology, Jagiellonian University, Kraków 30-387, Poland

Julia Korzuch - Institute of Chemistry, University of Silesia in Katowice, Katowice 40-007, Poland

Mateusz Dulski - Institute of Materials Engineering and Silesian Center for Education and Interdisciplinary Research, University of Silesia in Katowice, Chorzow 41-500, Poland

Robert Musiol - Institute of Chemistry, University of Silesia in Katowice, Katowice 40-007, Poland

Tadeusz Sarna - Faculty of Biochemistry, Biophysics, and Biotechnology, Jagiellonian University, Krakow 30-387, Poland

Complete contact information is available at:

https://pubs.acs.org/10.1021/acsbiomaterials.0c00932

\section{Author Contributions}

Design, conceptualization, and methodology: M.S., G.S.; chemical synthesis and characterization: M.S., J.K., and M.D.; Biophysical measurements: G.S.; Cellular experiments: O.K.K.; Writing and editing: M.S., G.S., R.M., and T.S.

\section{Notes}

The authors declare no competing financial interest. 


\section{ACKNOWLEDGMENTS}

M.S. thanks the National Science Center (Poland) for its support (Grant SONATA UMO-2016/23/D/NZ7/00912). M.D. is thankful for financial support from the National Science Center that was based on decision 2017/26/D/ST8/ 01117. Additionally, the authors want to thank Dr. Bujnowcz for his custom-written script for cell image analysis and Institute of Applied Radiation Chemistry from Lodz University of Technology (Poland) for providing us CBA probe.

\section{REFERENCES}

(1) Apalla, Z.; Lallas, A.; Sotiriou, E.; Lazaridou, E.; Ioannides, D. Epidemiological trends in skin cancer. Dermatology practical \& conceptual 2017, 7 (2), 1.

(2) Didona, D.; Paolino, G.; Bottoni, U.; Cantisani, C. Non melanoma skin cancer pathogenesis overview. Biomedicines 2018, 6 (1), 6 .

(3) Ting, P. T.; Kasper, R.; Arlette, J. P. Metastatic basal cell carcinoma: report of two cases and literature review. J. Cutaneous Med. Surg. 2005, 9 (1), 10-15.

(4) Toll, A.; Margalef, P.; Masferrer, E.; Ferrándiz-Pulido, C.; Gimeno, J.; Pujol, R. M.; Bigas, A.; Espinosa, L. Active nuclear IKK correlates with metastatic risk in cutaneous squamous cell carcinoma. Arch. Dermatol. Res. 2015, 307 (8), 721-729.

(5) Bastian, B. C. The molecular pathology of melanoma: an integrated taxonomy of melanocytic neoplasia. Annu. Rev. Pathol.: Mech. Dis. 2014, 9 (1), 239-271.

(6) Apalla, Z.; Nashan, D.; Weller, R. B.; Castellsague, X. Skin cancer: epidemiology, disease burden, pathophysiology, diagnosis, and therapeutic approaches. Dermatology and therapy 2017, 7 (1), 5-19.

(7) Christensen, E.; Warloe, T.; Kroon, S.; Funk, J.; Helsing, P.; Soler, A.; Stang, H.; Vatne, Ø.; Mørk, C. Guidelines for practical use of MAL-PDT in non-melanoma skin cancer. J. Eur. Acad. Dermatol. Venereol. 2010, 24 (5), 505-512.

(8) Jung, S. K.; Lee, K. W.; Byun, S.; Kang, N. J.; Lim, S. H.; Heo, Y.S.; Bode, A. M.; Bowden, G. T.; Lee, H. J.; Dong, Z. Myricetin suppresses UVB-induced skin cancer by targeting Fyn. Cancer Res. 2008, 68 (14), 6021-6029.

(9) Cranmer, L. D.; Engelhardt, C.; Morgan, S. S. Treatment of unresectable and metastatic cutaneous squamous cell carcinoma. Oncologist 2010, 15 (12), 1320.

(10) Safwat, M. A.; Soliman, G. M.; Sayed, D.; Attia, M. A. Fluorouracil-loaded gold nanoparticles for the treatment of skin cancer: development, in vitro characterization, and in vivo evaluation in a mouse skin cancer xenograft model. Mol. Pharmaceutics 2018, 15 (6), 2194-2205.

(11) Petrilli, R.; Eloy, J. O.; Saggioro, F. P.; Chesca, D. L.; de Souza, M. C.; Dias, M. V.S.; daSilva, L. L.P.; Lee, R. J.; Lopez, R. F.V. Skin cancer treatment effectiveness is improved by iontophoresis of EGFRtargeted liposomes containing 5-FU compared with subcutaneous injection. J. Controlled Release 2018, 283, 151-162.

(12) Shi, L.; Wang, X.; Tu, Q.; Wang, H.; Zhang, H.; Wang, P.; Zhang, L.; Huang, Z.; Wang, X.; Zhao, F.; Luan, H. Treating cutaneous squamous cell carcinoma using 5-aminolevulinic acid polylactic-co-glycolic acid nanoparticle-mediated photodynamic therapy in a mouse model. Int. J. Nanomed. 2015, 10, 347.

(13) Huang, P.; Xu, C.; Lin, J.; Wang, C.; Wang, X.; Zhang, C.; Zhou, X.; Guo, S.; Cui, D. Folic acid-conjugated graphene oxide loaded with photosensitizers for targeting photodynamic therapy. Theranostics 2011, 1, 240.

(14) Zhu, Z.; Tang, Z.; Phillips, J. A.; Yang, R.; Wang, H.; Tan, W. Regulation of singlet oxygen generation using single-walled carbon nanotubes. J. Am. Chem. Soc. 2008, 130 (33), 10856-10857.

(15) Mroz, P.; Pawlak, A.; Satti, M.; Lee, H.; Wharton, T.; Gali, H.; Sarna, T.; Hamblin, M. R. Functionalized fullerenes mediate photodynamic killing of cancer cells: Type I versus Type II photochemical mechanism. Free Radical Biol. Med. 2007, 43 (5), $711-719$

(16) Mroz, P.; Tegos, G. P.; Gali, H.; Wharton, T.; Sarna, T.; Hamblin, M. R. Photodynamic therapy with fullerenes. Photochemical \& Photobiological Sciences 2007, 6 (11), 1139-1149.

(17) Hamblin, M. R. Fullerenes as photosensitizers in photodynamic therapy: pros and cons. Photochemical \& Photobiological Sciences 2018, 17 (11), 1515-1533.

(18) Lee, J.; Mackeyev, Y.; Cho, M.; Li, D.; Kim, J.-H.; Wilson, L. J.; Alvarez, P. J. Photochemical and antimicrobial properties of novel C60 derivatives in aqueous systems. Environ. Sci. Technol. 2009, 43 (17), 6604-6610.

(19) Cho, M.; Lee, J.; Mackeyev, Y.; Wilson, L. J.; Alvarez, P. J.; Hughes, J. B.; Kim, J.-H. Visible light sensitized inactivation of MS-2 bacteriophage by a cationic amine-functionalized C60 derivative. Environ. Sci. Technol. 2010, 44 (17), 6685-6691.

(20) Liu, Y.; Jiao, F.; Qiu, Y.; Li, W.; Lao, F.; Zhou, G.; Sun, B.; Xing, G.; Dong, J.; Zhao, Y.; et al. The effect of Gd@ C82 (OH) 22 nanoparticles on the release of Th1/Th2 cytokines and induction of TNF- $\alpha$ mediated cellular immunity. Biomaterials 2009, 30 (23-24), $3934-3945$.

(21) Guan, M.; Zhou, Y.; Liu, S.; Chen, D.; Ge, J.; Deng, R.; Li, X.; Yu, T.; Xu, H.; Sun, D.; et al. Photo-triggered gadofullerene: enhanced cancer therapy by combining tumor vascular disruption and stimulation of anti-tumor immune responses. Biomaterials 2019, 213, 119218.

(22) Hamblin, M. R. Upconversion in photodynamic therapy: plumbing the depths. Dalton Transactions 2018, 47 (26), 8571-8580.

(23) Serda, M.; Ware, M. J.; Newton, J. M.; Sachdeva, S.; Krzykawska-Serda, M.; Nguyen, L.; Law, J.; Anderson, A. O.; Curley, S. A.; Wilson, L. J.; Corr, S. J. Development of photoactive Sweet-C60 for pancreatic cancer stellate cell therapy. Nanomedicine (London, U. K.) 2018, 13 (23), 2981-2993.

(24) Serda, M.; Malarz, K.; Mrozek-Wilczkiewicz, A.; Wojtyniak, M.; Musioł, R.; Curley, S. A. Glycofullerenes as non-receptor tyrosine kinase inhibitors-towards better nanotherapeutics for pancreatic cancer treatment. Sci. Rep. 2020, 10 (1), 1-11.

(25) Simões, M. F.; Sousa, J. S.; Pais, A. C. Skin cancer and new treatment perspectives: A review. Cancer Lett. 2015, 357 (1), 8-42.

(26) Chen, Y.; Miclea, R.; Srikrishnan, T.; Balasubramanian, S.; Dougherty, T. J.; Pandey, R. K. Investigation of human serum albumin (HSA) binding specificity of certain photosensitizers related to pyropheophorbide-a and bacteriopurpurinimide by circular dichroism spectroscopy and its correlation with in vivo photosensitizing efficacy. Bioorg. Med. Chem. Lett. 2005, 15 (13), 3189-3192.

(27) Belgorodsky, B.; Fadeev, L.; Ittah, V.; Benyamini, H.; Zelner, S.; Huppert, D.; Kotlyar, A. B.; Gozin, M. Formation and Characterization of Stable Human Serum Albumin- Tris-malonic Acid [C60] Fullerene Complex. Bioconjugate Chem. 2005, 16 (5), 1058-1062.

(28) Krumkacheva, O. A.; Timofeev, I. O.; Politanskaya, L. V.; Polienko, Y. F.; Tretyakov, E. V.; Rogozhnikova, O. Y.; Trukhin, D. V.; Tormyshev, V. M.; Chubarov, A. S.; Bagryanskaya, E. G.; et al. Triplet Fullerenes as Prospective Spin Labels for Nanoscale Distance Measurements by Pulsed Dipolar EPR Spectroscopy. Angew. Chem. 2019, 131 (38), 13405-13409.

(29) Qu, X.; Komatsu, T.; Sato, T.; Glatter, O.; Horinouchi, H.; Kobayashi, K.; Tsuchida, E. Structure, photophysical property, and cytotoxicity of human serum albumin complexed with tris (dicarboxymethylene)[60] fullerene. Bioconjugate Chem. 2008, 19 (8), 15561560.

(30) Gebicki, J. M. Oxidative stress, free radicals and protein peroxides. Arch. Biochem. Biophys. 2016, 595, 33-39.

(31) Gutteridge, J. Lipid peroxidation and antioxidants as biomarkers of tissue damage. Clin. Chem. 1995, 41 (12), 1819-1828.

(32) Wang, F.; Good, J. A.; Rath, O.; Kaan, H. Y. K.; Sutcliffe, O. B.; Mackay, S. P.; Kozielski, F. Triphenylbutanamines: kinesin spindle protein inhibitors with in vivo antitumor activity. J. Med. Chem. 2012, 55 (4), 1511-1525. 
(33) Snyder, J. W.; Lambert, J. D.; Ogilby, P. R. 5, 10, 15, 20Tetrakis (N-Methyl-4-Pyridyl)-21 H, 23H-Porphine (TMPyP) as a Sensitizer for Singlet Oxygen Imaging in Cells: Characterizing the Irradiation-dependent Behavior of TMPyP in a Single Cell. Photochem. Photobiol. 2006, 82 (1), 177-184.

(34) Korytowski, W.; Bachowski, G. J.; Girotti, A. W. Analysis of cholesterol and phospholipid hydroperoxides by high-performance liquid chromatography with mercury drop electrochemical detection. Anal. Biochem. 1993, 213 (1), 111-119.

(35) Michalski, R.; Zielonka, J.; Gapys, E.; Marcinek, A.; Joseph, J.; Kalyanaraman, B. Real-time measurements of amino acid and protein hydroperoxides using coumarin boronic acid. J. Biol. Chem. 2014, 289 (32), 22536-22553.

(36) Sies, H. Ebselen, a selenoorganic compound as glutathione peroxidase mimic. Free Radical Biol. Med. 1993, 14 (3), 313-323.

(37) Olchawa, M.; Krzysztynska-Kuleta, O.; Duda, M.; Pawlak, A.; Pabisz, P.; Czuba-Pelech, B.; Sarna, T. In vitro phototoxicity of rhodopsin photobleaching products in the retinal pigment epithelium (RPE). Free Radical Res. 2019, 53 (4), 456-471.

(38) Huang, L.-K.; Wang, M.-J. J. Image thresholding by minimizing the measures of fuzziness. Pattern recognition 1995, 28 (1), 41-51.

(39) Sharma, S. K.; Chiang, L. Y.; Hamblin, M. R. Photodynamic therapy with fullerenes in vivo: reality or a dream? Nanomedicine (London, U. K.) 2011, 6 (10), 1813-1825.

(40) Ashcroft, J. M.; Tsyboulski, D. A.; Hartman, K. B.; Zakharian, T. Y.; Marks, J. W.; Weisman, R. B.; Rosenblum, M. G.; Wilson, L. J. Fullerene (C60) immunoconjugates: interaction of water-soluble C60 derivatives with the murine anti-gp240 melanoma antibody. Chem. Commun. 2006, No. 28, 3004-3006.

(41) Lapin, N. A.; Vergara, L. A.; Mackeyev, Y.; Newton, J. M.; Dilliard, S. A.; Wilson, L. J.; Curley, S. A.; Serda, R. E. Biotransport kinetics and intratumoral biodistribution of malonodiserinolamidederivatized [60] fullerene in a murine model of breast adenocarcinoma. Int. J. Nanomed. 2017, 12, 8289.

(42) Chen, M.; Zhou, S.; Guo, L.; Wang, L.; Yao, F.; Hu, Y.; Li, H.; Hao, J. Aggregation Behavior and Antioxidant Properties of Amphiphilic Fullerene C60 Derivatives Cofunctionalized with Cationic and Nonionic Hydrophilic Groups. Langmuir 2019, 35 (21), 6939-6949.

(43) Krueger, P. J.; Jan, J. Infrared spectra and the molecular conformations of some aliphatic amines. Can. J. Chem. 1970, 48 (20), 3229-3235.

(44) McKean, D.; Duncan, J.; Batt, L. CH stretching frequencies, bond lengths and dissociation energies. Spectrochimica Acta Part A: Molecular Spectroscopy 1973, 29 (6), 1037-1049.

(45) Socrates, G. Infrared and Raman Characteristic Group Frequencies: Tables and Charts; John Wiley \& Sons: New York, 2004.

(46) Craig, N. C.; Evans, D. A. Infrared and Raman Spectra of cisand trans-1,2-Dichloro-1,2-difluoroethylene. J. Am. Chem. Soc. 1965, 87 (19), 4223-4230.

(47) Long, F.; Bakule, R. Keto-Enol Transformation of 1, 2Cyclohexanedione. II. Acid Catalysis in Strongly Acidic Media 1-3. J. Am. Chem. Soc. 1963, 85 (15), 2313-2318.

(48) Campbell, R.; Gilow, H. $\beta$-Diketones. III. 1, 2 The Effect of Ring Size and Conjugation on Tautomerism. J. Am. Chem. Soc. 1962, 84 (8), 1440-1443.

(49) Buettner, G. R.; Mason, R. P. Spin-trapping methods for detecting superoxide and hydroxyl free radicals in vitro and in vivo. Critical reviews of oxidative stress and aging: advances in basic science, diagnostics and intervention 2002, 1, 27-38.

(50) Nonell, S.; Redmond, R. On the determination of quantum yields for singlet molecular oxygen photosensitization. J. Photochem. Photobiol., B 1994, 22 (2), 171-172.

(51) Gimenez, R. E.; Vargova, V.; Rey, V.; Turbay, M. B. E.; Abatedaga, I.; Moran Vieyra, F. E.; Paz Zanini, V. I.; Mecchia Ortiz, J. H.; Katz, N. E.; Ostatna, V.; et al. Interaction of singlet oxygen with bovine serum albumin and the role of the protein nanocompartmentalization. Free Radical Biol. Med. 2016, 94, 99-109.
(52) Vakrat-Haglili, Y.; Weiner, L.; Brumfeld, V.; Brandis, A.; Salomon, Y.; Mcllroy, B.; Wilson, B. C.; Pawlak, A.; Rozanowska, M.; Sarna, T.; et al. The microenvironment effect on the generation of reactive oxygen species by Pd- bacteriopheophorbide. J. Am. Chem. Soc. 2005, 127 (17), 6487-6497.

(53) Ashur, I.; Goldschmidt, R.; Pinkas, I.; Salomon, Y.; Szewczyk, G.; Sarna, T.; Scherz, A. Photocatalytic generation of oxygen radicals by the water-soluble bacteriochlorophyll derivative WST11, noncovalently bound to serum albumin. J. Phys. Chem. A 2009, 113 (28), $8027-8037$

(54) Leonis, G.; Avramopoulos, A.; Papavasileiou, K. D.; Reis, H.; Steinbrecher, T.; Papadopoulos, M. G. A comprehensive computational study of the interaction between human serum albumin and fullerenes. J. Phys. Chem. B 2015, 119 (48), 14971-14985.

(55) Di Giosia, M.; Bomans, P. H.; Bottoni, A.; Cantelli, A.; Falini, G.; Franchi, P.; Guarracino, G.; Friedrich, H.; Lucarini, M.; Paolucci, F.; et al. Proteins as supramolecular hosts for C 60: a true solution of C 60 in water. Nanoscale 2018, 10 (21), 9908-9916.

(56) Soldà, A.; Cantelli, A.; Di Giosia, M.; Montalti, M.; Zerbetto, F.; Rapino, S.; Calvaresi, M. C 60@ lysozyme: a new photosensitizing agent for photodynamic therapy. J. Mater. Chem. B 2017, 5 (32), 6608-6615.

(57) Raoof, M.; Mackeyev, Y.; Cheney, M. A.; Wilson, L. J.; Curley, S. A. Internalization of C60 fullerenes into cancer cells with accumulation in the nucleus via the nuclear pore complex. Biomaterials 2012, 33 (10), 2952-2960.

(58) Zhao, Z.; Fairchild, P. W. In Dependence of Light Transmission through Human Skin on Incident Beam Diameter at Different Wavelengths, Laser-Tissue Interaction IX; International Society for Optics and Photonics: 1998; pp 354-360. 